\title{
Development of Wind Energy and the Installed Wind Power Plants in Turkey
}

\author{
Cansev Genç ${ }^{1 *}$, Abdulla Sakalli ${ }^{1}$, Ivaylo Stoyanov², Teodor Iliev², Grigor Mihaylov ${ }^{3}$, and \\ Ivan Beloev ${ }^{2}$ \\ ${ }^{1}$ Iskenderun Technical University, Dept. of Industrial Engineering, Turkey \\ ${ }^{2}$ University of Ruse, 8, Studentska Street, 7017 Ruse, Bulgaria \\ ${ }^{3}$ University of Telecommunications and Post, 1 Acad. Stefan Mladenov Str., Bulgaria
}

\begin{abstract}
This article analyses the development of wind energy in Turkey - the number and capacity of installed wind generators, as well as the generated electricity. It was established that the number of wind power plants is 99 with a total installed capacity of $3933 \mathrm{MW}$, and the amount of electricity produced by wind power plants is $17909.3 \mathrm{GWh} /$ year. Turkey has been shown to have great potential for developing electricity generation from offshore wind farms. The increase in the number of offshore wind turbines in the coming years is expected to increase the relative share of renewable sources in the country's energy mix, to contribute to the technological and industrial development of the regions, to produce electricity from renewable and environmentally friendly sources and to reduce the country's energy dependence. It has been established that there are appropriate conditions in Turkey for the development of wind energy and preconditions have been created for achieving the target for promoting the use of renewable energy sources by 2023 .
\end{abstract}

\section{Introduction}

Climate change, ensuring energy supply and enough food for the population are the main problems that modern society has to deal with. In this regard, the energy sector has a key place in the modern world within Fourth Industrial Revolution period (Industry 4.0) and also is the basis of overall economic development. The forecasts are that in recent years with the development of technology, the number of devices that work with electricity in the household, industry, and transport sector will constantly increase. That means that more electricity needs to be produced. The advantage of electricity is that it can be transported quickly over long distances, easily transformed into another type of energy, and is an environmentally friendly resource, even though production sometimes pollutes the environment (for example CHP) [5, 6, 8].

Conditional energy sources can be divided into non-renewable and renewable. Currently, it has been found that approximately $85 \%$ of the world energy consumption demand comes from fossil fuels (coal, oil, natural gas), which belong to the group of nonrenewable energy sources $[1,2]$. The main disadvantages of these sources are that the

${ }^{*}$ Correspondingauthor: genccansev@gmail.com 
stocks of these raw materials are constantly declining and their price is constantly increasing. Besides, ensuring the ever-increasing consumption of non-renewable energy sources is a prerequisite for climate change and devastating consequences for the environment.

In this regard, the national legislation of the developed countries encourages the development of energy policies based on renewable energy sources (RES) and technologies. Increasing the use of RES is central to the European Union's energy policy, expected to contribute both to reducing greenhouse gas emissions, the security of energy supply and to creating new jobs. Accordingly, the European Union (EU) has set as a target reducing greenhouse gas emissions by $40 \%$ below 1990 levels by 2030 , the share of energy from renewable sources to be at least $27 \%$ and new indicators for building a competitive and secure energy system [3]. Thus, it is expected to bring significant benefits to the trade energy balance, the use of local energy sources, increased employment, and economic growth within the EU. The achievement of the EU's renewable energy target is ensured through a management system based on national and regional energy plans.

The way, we reduce our commitment to fossil fuel use, will help countries succeed in energy diplomacy and reduce their dependence on exports. Increasing the share of renewable energy sources could be completed with the active support of local and national authorities through the implementation of a set of legislative measures aimed at industry, household consumers and transport. These resources are at low cost to use, easy to produce and show positive results shortly after investment $[4,7]$.

Wind energy is considered as an alternative energy resource to fossil fuels [5]. The most important feature that distinguishes renewable energy from other sources is itsability to constantly renew itself. This study aims to examine the installed power plants and evaluated the possibility of wind energy as a suitable RES for electricity generation in Turkey.

\subsection{Environmental and Sustainable Development}

In recent years, energy efficiency and renewable energy have become important issues of energy policy, and have become major tools for reducing greenhouse gas emissions. Vigorous action is being taken to promote clean energy at the local and national level. Our experience shows that the integration of energy in local plans and strategies for sustainable development is a key condition for the rational use of energy at the local level, which at the same time reflects on many social issues such as education, health, unemployment, and others.

A key tool for sustainable development is energy planning. Without initial planning efforts, the energy system cannot achieve an optimal balance between production and consumption. Programming is the second step of the process, which uses the results of energy planning as a framework (potentials and goals) and proposes the measures, tools, and financial resources to achieve the set goals. Energy planning and programming of energy consumption in real conditions take place in three stages: data collection, modeling and forecasting, and programming.

The concept of sustainable development is based on the principle that development must meet today's needs without compromising the prospects of future generations, including energetics.

Building a progressively integrated energy market requires a rethinking of national energy strategies, which are largely losing their traditional boundaries and becoming part of a global energy strategy, following security of supply priorities; competitiveness, and environmental protection.

Sustainable development is a way of using natural resources that aims to meet human needs while maintaining the natural balance in the environment so that these needs can be 
met both now and in the future. To achieve sustainable development, it is necessary to invest in natural resources, in the prevention of industrial accidents and social capital.

The use of energy consists of the conversion of wind into mechanical energy by a wind turbine [10]. The main advantages of using wind energy are:

- no emissions of pollutants and greenhouse gases;

- $\quad$ wind energy is generated without leaving waste products;

- the recent reduction in the unit cost of energy produced in modern wind farms.

Disadvantages of using wind energy:

- the relatively high cost of energy produced and low reliability of the turbine;

- $\quad$ visual negative and noise impact on people;

- the impact of the environment and the surrounding ecosystems and require large free areas for their installation;

- $\quad$ their work depends significantly on wind speed.

Another disadvantage is that only part of the wind energy is converted into mechanical energy, which depends on the aerodynamic performance of the blades [11]. In practice, wind generators convert $\% 30$ of the maximum possible power.

To achieve the goal of the study, various sources of wind data can be used - global, national, and regional estimates of wind resources. The most accurate data for forecasting the production of wind turbines is achieved by using data from measurements made at the site of installation of the turbine. Fig. 1 shows a map with Turkey's technical wind potential in offshore areas. The estimated technical potential for fixed and floating offshore wind in Turkey amounts to $75 \mathrm{GW}$, which is a good opportunity for the development of wind energy.

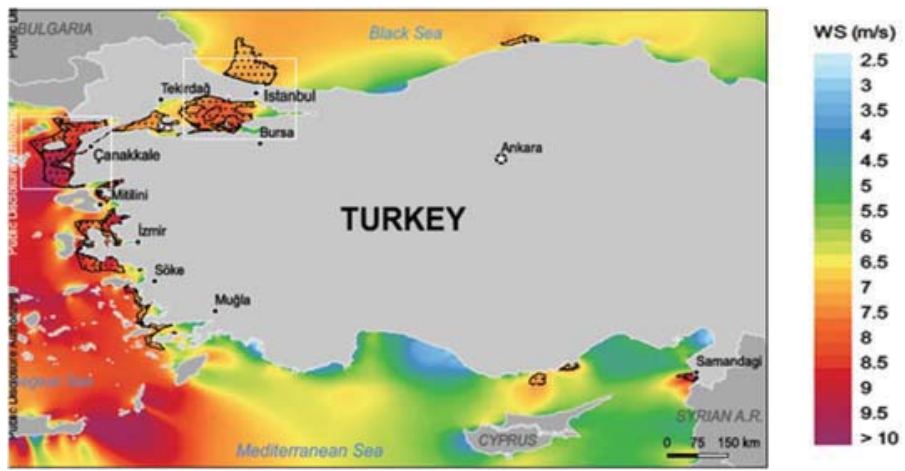

Fig. 1.Turkey`s offshore wind technical potential [12].

\section{Material and Methods}

According to Turkish Electricity Transmission Company,the data announced by (TETC) and studies made in [13], the installed power of wind turbines in Turkey is $3933 \mathrm{MW}$ and the total number of power plants is 99. Also, according to the data of 2015 [14] the power of wind turbines represents $5.5 \%$ of the total installed capacity (coal, wind, gas, solar and water) in Turkey [14]. It has been found by the Turkish Wind Energy Statistics Report 2018 , the amount of electricity generated from wind power plants is $17909.3 \mathrm{GWh}[7,15]$.

According to the Ministry of Energy and Natural Resources at the end of 2018, the energy emitted by RES in the transmission network is $95728.50 \mathrm{GWh}[5,16]$. This represents $31.5 \%$ of the energy produced in the country, ie. they have a significant relative 
share in the energy mix, the energy obtained from fossil fuels represents $67.1 \%$. This shows that most of the electricity is produced from traditional energy sources. A more in-depth analysis of the data shows that the relative share of types of renewable sources they are distributed as follows (Fig. 2): Hydro Power - 10.70\%; Wind Power - 2.50\%; Geothermal $11.30 \%$; Solar Energy - 1.60\%; Biomass and others - 5.40\%.

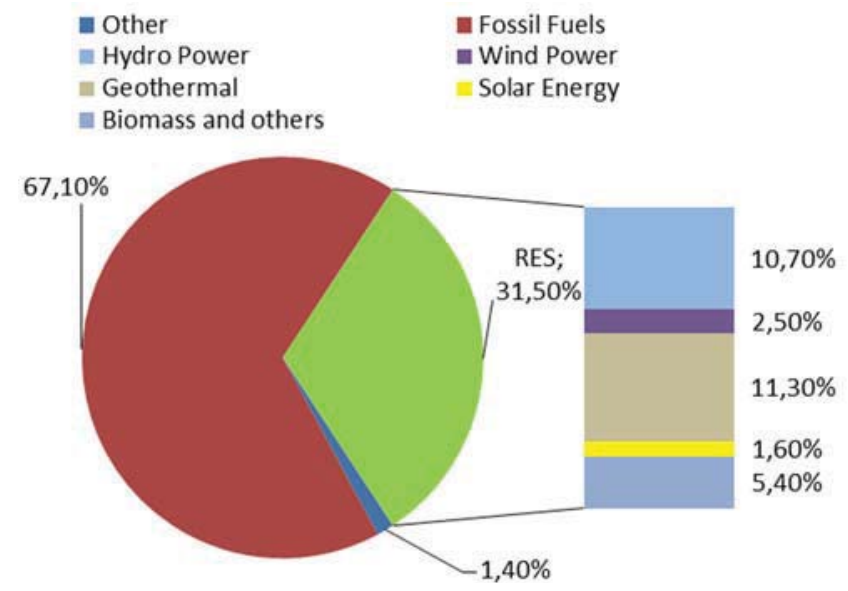

Fig. 2.Distribution of the types of electricity production by sources for 2018

\section{Results}

To increase the use of RES and regional development, Turkey has adopted many strategic documents and actions for the growth of renewable energy. One of them is the Strategic Plan (Ministry Of Energy And Natural Resources | 2019-2023 Strategic Plan).

In his study Durmuşoğlu [18], said that it is likely Turkey to examine its energy policies on two issues. The first of them is to achieve the goal of the Central country by increasing energy diversity, to ensure energy supply security. The second is that it aims to maximize energy efficiency by activating existing green energy sources, namely renewable energy sources, in green energy. In this respect, the main goal is to be "Energy Center and Energy Corridor".

Turkey has specific action plans and strategy documents on green energy, such as these targets. One of them is the National Renewable Energy Action Plan (UYEEP), a document that sets up strategies to encourage the development of new renewable energy in Turkey. These strategies have been created for the following purposes [19]:

- To increase the share of electricity generation based on RES to at least $30 \%$ of total production by 2023;

- The overall goal is to provide $20 \%$ of the total energy demand from RES.

- To contribute to technological and industrial development by achieving higher renewable energy installed power by 2023.

Another important document is Turkey's Energy Efficiency Strategy Document. It refers to the improvement of Turkey's energy efficiency in the period 2012-2023. This document sets out two key objectives directly related to renewable energy. The first concerns the higher relative share of renewable energy sources, and the second - to minimize the negative environmental impacts of activities in the energy sector. The set goals are to increase the installed capacity from renewable energy sources to $34000 \mathrm{MW}$ by 2023.

As a result of the legislative measures taken by the government as shown in Fig. 3, the cumulative installation for wind power plants in Turkey has been increased in the last 10 
years. The increase of the installed capacity of Wind Power Plant (WPP) is from $364 \mathrm{MWm}$ in 2008 to $7615 \mathrm{MWm}$ in 2019.

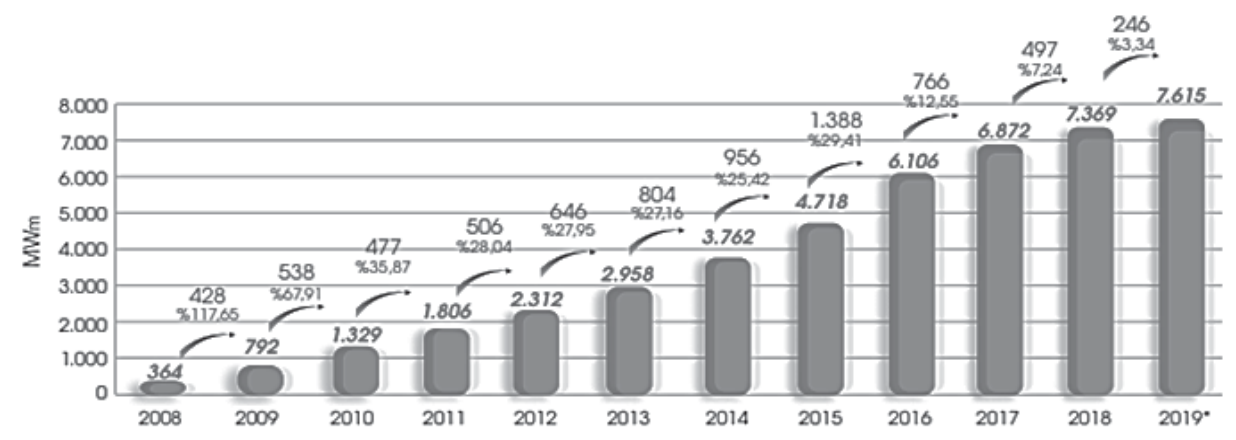

Fig. 3. Cumulative Installations for WPP in Turkey (Source: Turkish Wind Energy Statistic Report, 2019).

Over the last decade, there has been a positive trend in both the number and the installed capacity of WPP. At the beginning of the observed period, the increase is the largest, as after 2011 there is a relatively constant growth rate of about $26 \%$ per year. There has been some slowdown since 2016, but overall the cumulative Installations for WPP in Turkey have had positive growth.

Suitable places for the development of wind energy are the offshore zones of Turkey, which have a high wind potential (Fig. 4). However, the installed capacities are relatively small, but it is expected that these capacities will be increased in the coming years.

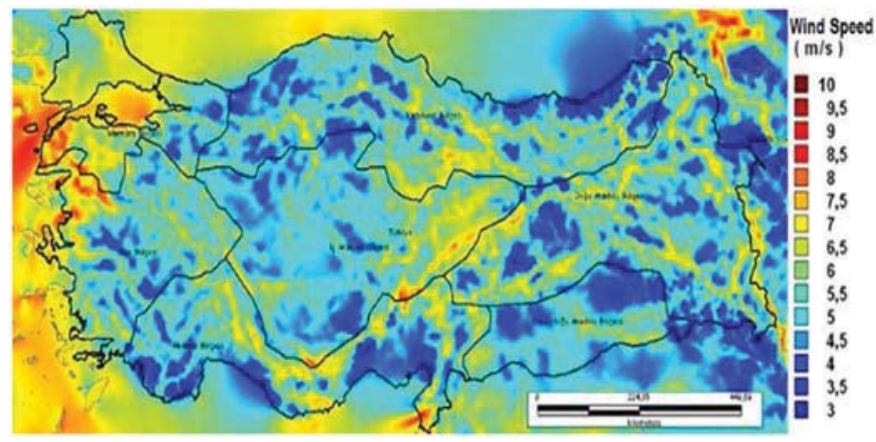

Fig. 4. Wind Atlas of Turkey (Source:General Directorate of Energy Affairs, REPA)

Fig. 4 shows that the Marmara, Aegean, and the Eastern Mediterranean region have a high potential of wind energy. According to REPA's work According to Turkey wind potential and that potential is estimated to be $131756.40 \mathrm{MW}$.

Appropriate measures for the development of wind energy and renewable energy sources have been adopted and are being implemented in the country. For Turkey to achieve the desired success in wind energy, it must achieve the goals set in the national strategic documents. In this way, a clean and renewable energy source will be provided, energy security will be improved and the favorable location of the country for the production of electricity from wind generators will be used.

\section{Conclusion}

Turkey has been found to have adequate potential to install wind turbines in offshore areas. Some normative documents have been adopted to encourage the use of renewable energy 
sources. Using the potential of wind will contribute to the development of the regions, improve energy security, energy production close to consumers, and reduce the number of carbon emissions into the atmosphere. Moreover, it will improve the quality of the environment and energy independence and create conditions for quality retrieves of people's lives.

In renewable energy sources such as solar, wind, hydropower, geothermal, biomass, wave and current, we have a significant potential in terms of both electric power generation and heat generation. But in order for this potential to be fully realized, it is necessary to develop financing opportunities, update legislation, strengthen transmission infrastructure and increase investor awareness.

The objectives of the 2019-2023 strategic plan are as follows: ensuring sustainable energy supply security, priority and increase in energy efficiency, strengthening institutional and sectoral capacity, increasing regional and global efficiency in energy and natural resources, improving technology and localization, improving predictability, increasing production capacity with sustainable mining in markets.

The objectives of the 2019-2023 Strategic Plan are as follows: The total power rate of electricity board power based on domestic and renewable energy sources will be increased from $59 \%$ to $65 \%$. Technological transformation applications will be made in the electricity sector. Energy system planning will be made for electric vehicles. Strategies will be implemented to develop cooperation and investment opportunities with target countries in priority areas. Efforts will continue to make our country an energy trade center. Efforts will continue to increase the domestic production rate used in the field of energy and natural resources.

The strengths of our ministry with the 2019-2023 strategic plan; High potential for domestic and renewable resources (hydraulics, solar, wind, geothermal, coal, biomass, marble, boron, rare earth elements), which find an investment environment for solar, wind and geothermal resources in our country, and to carry out studies aimed at ensuring diversity with sustainable energy supply security, etc. Weaknesses; lack of energy resources to meet the demand in our country, inability to reach sufficient levels in the production of high added value-added products, low production of domestic primary energy sources.

This paper including some part of Master's Degree Thesis of Cansev Genç.

\section{References}

1. M. T. Çakır, Turkey's wind energy potential and its place in the EU countries. Pol. J, 13(4), 287-293 (2010)

2. B. Yelmen, M. T. Çakır, Green energy resources and technologies; II. Proceedings of the National Congress of Electrical Installation - Emo; Izmir, (2011)

3. European Commission. A policy framework for climate and energy in the period from 2020 to 2030. Brussels, 15 finalCOM (2014)

4. E. Ürün, E. Soyu, A Review of the Renewable Energy Resources in the Energy Production of Turkey. Dumlupınar University J. Soc. Sci, 31-45 (2016)

5. İ. Mert, C. Karakuş, F. Peker, Investigation of wind characteristics of Antakya region. J. Irrigation and Drainage Eng. 5(1),13-22 (2014)

6. C. Erdin, G. Özkaya, Turkey’s 2023 Energy Strategies and Investment Opportunities for Renewable Energy Sources: Site Selection Based on ELECTRE. Sustainability 11, $2136(2019)$

7. A. Koç, H. Yağlı, Y. Koç, İ. Uğurlu, General Evaluation of Energy Outlook in Turkey and the World, Eng. Mach, 59 (692), 86-114 (2018) 
8. K. Kaya, M. C. Şenel, E. Koç, Turkey and the world' Evaluation of Renewable Energy Sources, Tech. App. Sci, 13(3),219-234 (2018)

9. Europe's onshore and offshore wind energy potential. EEA Technical Report No.690(2009).

10. H. N. Bayraç, Global wind energy policies and applications, Uludağ J. Eco. Soc. , 30(1), 37-57 (2011)

11. A. Terziev, Wind flow behavior prediction over complex terrains in respect with orography, International Conference on ENERGY and ENVIRONMENT (CIEM), Timisoara, Romania, 2019, pp. 90-94, doi: 10.1109/CIEM46456.2019.8937627. (2019)

12. Turkey_Offshore-Wind-Technical-Potential_WBG-ESMAP. https://energydata.info/dataset/offshore-wind̄-technical-potential/ (accessed on 05/04/20)

13. F. Karık, A. Sözen, Ü. İskender, Current Status of Wind Energy in Turkey, J. Gazi Eng Sci, 1(2), 219-234 (2015)

14. Turkish Electricity Transmission Company (TETC). https://www.teias.gov.tr/tr-TR/ (accessed on 12/04/20)

15. K. Kaya, M. C. Şenel, E. Koç, Turkey and the world' Evaluation of Renewable Energy Sources, Tech App. Sci, 13(3), 219-234 (2018)

16. Ministry of Energy and Natural Resources. https://www.enerji.gov.tr/(accessed on $12 / 04 / 20)$

17. MENR. Strategic Plan. Available online: www.enerji.gov.tr/tr-TR/Stratejik-Plan (accessed on 08/09/20)

18. S. Durmuşoğlu, Turkey's energy policy and its effects on international relations with neighboring countries (Master's thesis, Istanbul Commerce University), 111 (2015)

19. A. Arık, Sustainability of renewable energy policies: An evaluation in terms of EU countries and Turkey (Master's thesis, Ordu University Institute of Science) 106 (2016) 